\title{
Standardized test for anti-Tr/DNER in patients with paraneoplastic cerebellar degeneration
}

\section{OPEN}

Christian Probst, $\mathrm{PhD}^{*}$

Lars Komorowski, PhD*

Esther de Graaff, PhD

Marleen van Coevorden-

Hameete, MD

Veronique Rogemond,

$\mathrm{PhD}$

Jerome Honnorat, MD

Lidia Sabeter, MD

Francesc Graus, MD

Sven Jarius, MD

Raymond Voltz, MD

Brigitte Wildemann, MD

Diego Franciotta, MD

Inga M. Blöcker, PhD

Wolfgang Schlumberger,

$\mathrm{PhD}$

Winfried Stöcker, MD

Peter A.E. Sillevis Smitt, MD

Correspondence to

Dr. Komorowski:

1.komorowski@euroimmun.de

\section{ABSTRACT}

Objective: To determine sensitivity and specificity of a standardized recombinant cell-based indirect immunofluorescence assay (RC-IFA) for anti-Tr antibodies in comparison to a reference procedure.

Methods: Delta/Notch-like epidermal growth factor-related receptor (DNER) was expressed in HEK293 and used as a substrate for RC-IFA. HEK293 control cells expressing CDR2/Yo and CDR2L as well as mock-transfected HEK293 cells were used as controls. Serum samples from 38 patients with anti-Tr antibodies (33 with paraneoplastic cerebellar degeneration [PCD] and Hodgkin lymphoma), 66 patients with anti-Tr-negative PCD, 53 patients with Hodgkin lymphoma without neurologic symptoms, 40 patients with rheumatic diseases, and 42 healthy blood donors were tested for anti-DNER reactivity in the RC-IFA. In addition, RC-IFA results were compared to those from a commercial tissue-based IFA using monkey cerebellum.

Results: Using the RC-IFA, anti-DNER was detected in all anti-Tr-positive patients but in none of the controls (sensitivity 100\%, 95\% confidence interval [Cl] 92.8\%-100\%; specificity 100\%, 95\% Cl 98.7\%-100\%). In comparison, anti-Tr was not detected in 4 samples with low-titer autoantibodies using the commercial tissue-based assay. Preadsorption of sera with either recombinant full-length DNER or its extracellular domain selectively abolished anti-Tr reactivity.

Conclusion: Anti-Tr antibodies bind to the extracellular domain of DNER and can be detected by RC-IFA using HEK293 cells expressing the recombinant receptor. The new method performs better than a frequently used commercial tissue-based indirect immunofluorescence assay (IFA) in samples with low-titer antibodies.

Classification of evidence: This study provides Class II evidence that RC-IFA accurately detects anti-Tr as compared to conventional IFA. Neurol Neuroimmunol Neuroinflamm 2015;2:e68; doi: 10.1212/NXI.0000000000000068

\section{GLOSSARY}

$\mathbf{C I}=$ confidence interval; DNER = Delta/Notch-like epidermal growth factor-related receptor; $\mathbf{H L}=$ Hodgkin lymphoma; IFA = indirect immunofluorescence assay; PBS = phosphate-buffered saline; PCD = paraneoplastic cerebellar degeneration; RCIFA $=$ recombinant cell-based indirect immunofluorescence assay; $\mathbf{S C L C}=$ small cell lung cancer.

Many patients with neurologic syndromes like paraneoplastic cerebellar degeneration (PCD) have autoantibodies against neural antigens in their serum and/or CSF. PCD develops either as part of a more widespread encephalomyelitis, e.g., in patients with anti-Hu antibodies, or as an isolated syndrome, e.g., in patients with anti-Yo, anti-Ri, or anti-Tr antibodies. ${ }^{1}$ The isolated syndrome is one of the best-characterized paraneoplastic neurologic syndromes, and

\footnotetext{
*These authors contributed equally to this manuscript.

From the Institute of Experimental Immunology (C.P., L.K., I.M.B., W. Schlumberger, W. Stöcker), Euroimmun AG, Lübeck, Germany; Department of Biology (E.d.G., M.v.C.-H.), Division of Cell Biology, Utrecht University, the Netherlands; Department of Neurology (M.v.C.-H., P.A.E.S.S.), Erasmus MC, Rotterdam, the Netherlands; Neuro-oncology Department (V.R., J.H.), French Paraneoplastic Neurological Syndrome Reference Center, Hospices Civils de Lyon, Hôpital Neurologique, Bron, France; Lyon Neuroscience Research Center (V.R., J.H.), INSERM U1028/CNRS UMR 5292, Lyon, France; University of Claude Bernard (V.R., J.H.), Lyon 1, Villeurbanne, France; Institut d’ Investigació Biomèdica August Pi i Sunyer (IDIBAPS) (L.S., F.G.), Barcelona, Spain; Department of Molecular Neuroimmunology (S.J., B.W.), University of Heidelberg, Germany; Department of Palliative Medicine (R.V.), University Hospital Cologne, Germany; and IRCCS (D.F.), C. Mondino National Neurological Institute, Pavia, Italy.

Go to Neurology.org/nn for full disclosures. Funding information and disclosures deemed relevant by the authors, if any, are provided at the end of the article. The Article Processing Charge was paid by Euroimmun AG.

This is an open access article distributed under the terms of the Creative Commons Attribution-Noncommercial No Derivative 3.0 License, which permits downloading and sharing the work provided it is properly cited. The work cannot be changed in any way or used commercially.
} 
when subacute severe ataxia develops in an adult patient, an immediate search for an underlying neoplasm is required. ${ }^{1,2}$ Knowing the type of antibody can guide that search. ${ }^{3}$ Isolated PCD is most commonly associated with ovarian cancer, breast cancer, small cell lung cancer (SCLC), or Hodgkin lymphoma (HL). ${ }^{4}$

The association of HL with PCD was first described in $1966,{ }^{5}$ and subsequently antibodies against cerebellar Purkinje cells (termed anti-Tr or PCA-Tr) were identified. ${ }^{6}$ Anti-Tr autoantibodies are characterized based on (1) their well-defined immunostaining pattern; (2) their frequent association with HL; (3) their association with a so-called "well-characterized neurological syndrome," as defined in reference 3; (4) the unambiguous identification of these antibodies in independent studies by more than one laboratory; and (5) the low frequency of these antibodies in patients without cancer. ${ }^{2}$

Anti-Tr antibodies are defined by a specific staining pattern in cerebellar tissue that is characterized by punctate immunoreactivity in both the dendritic tree and soma of Purkinje cells but not in their axons. ${ }^{7,8}$ This characteristic pattern is indicative of the presence of anti-Tr antibodies. Some laboratories encourage further confirmation of the finding by epitope blocking, which is impractical in a routine diagnostic setting. ${ }^{9}$ In order to resolve this situation, the $\operatorname{Tr}$ antigen has been sought since the initial description of the anti- $\operatorname{Tr}$ pattern. Recently, the Delta/Notch-like epidermal growth factor-related receptor (DNER) was identified as the target antigen of anti- $\mathrm{Tr}$ antigen by using immunoprecipitation and then mass spectrometry. ${ }^{10}$ In the meantime, this finding was confirmed in an independent study. ${ }^{11}$ Using deletion constructs, the main epitope of DNER was pinpointed to the extracellular domain. ${ }^{10}$

Now that DNER has been identified as the target antigen of anti-Tr, we are able to develop a standardized recombinant cell-based indirect immunofluorescence assay (RC-IFA). ${ }^{10}$ In the present study, we evaluate the sensitivity and specificity of such an RC-IFA using standardized dried test systems together with a large set of well-defined anti-Tr-positive sera and controls in comparison to indirect immunofluorescence assay (IFA) using cryosections of mammalian cerebellum. We show that the new DNER assay has high sensitivity and specificity and performs better than the classic IFA using dried mammalian cerebellar cryosections that is currently used in many laboratories to determine anti-Tr.

METHODS Human sera. Anonymized sera from 38 patients with PCD were sent under code to Euroimmun by centers in the Netherlands, France, Spain, Germany, and Italy for confirmatory anti-DNER testing. All sera had previously tested positive for anti- $\mathrm{Tr}$ in the contributing laboratories, either by conventional immunohistochemistry or by tissue-based IFA using cryosections of rat cerebellum, according to published criteria for anti-Tr staining. ${ }^{8} 12$ Positive results were confirmed in most cases by epitope blocking, as described. ${ }^{9}$ Clinical information was obtained from forms filled out by the referring neurologists, telephone interviews, and review of the clinical records. ${ }^{12}$ The majority of patients (33) were diagnosed with PCD and HL. The remaining 5 samples included 1 patient with PCD without a confirmed tumor, 1 with limbic encephalitis and HL, 1 with paraneoplastic encephalomyelitis and HL, 1 with HL only, and 1 with unknown diagnosis. Five samples from patients with cerebellar ataxia were originally included as disease controls in a study evaluating the utility of antineuronal antibody testing in neuromyelitis optica (S.J. and B.W., unpublished data); these samples were tested in an anonymized fashion. In addition, serum samples from 207 controls were tested. Controls included 66 patients with $\mathrm{PCD}$ with a variety of tumors but no anti-Tr antibodies: 25 with non-HL, 12 with HL, 7 with breast cancer, 6 with nonSCLC, 3 with ovarian cancer, and 13 with other tumors. Furthermore, 53 patients with HL without neurologic symptoms were enrolled, as were 46 patients with other diseases (20 rheumatoid arthritis, 10 systemic lupus erythematosus, 10 Sjögren syndrome, 4 encephalitis, 2 neuropathy) and 42 healthy individuals.

Standard protocol approvals, registrations, and patient consents. Testing was approved by the institutional review boards of the participating institutions. Informed consent was obtained from all patients whose material was used in this study.

Cloning and expression of DNER in HEK293. The cDNAs for human DNER (UNIPROT Q8NFT8), its extracellular domain (DNER[ec]: amino acids 1-640), CDR2 (Q01850), or CDR2L (Q86X02) were obtained by performing PCR on a commercially available cDNA (BioSource, Solingen, Germany, Genbank BC035009; BC017503; BC047534). The amplification products were ligated with pTriEx-1 (Merck Biosciences, Darmstadt, Germany). DNER, DNER(ec), CDR2/Yo, or CDR2L (each with C-terminal octahistidine-tags) was expressed in human HEK293 cells after ExGen500-mediated transfection (Fermentas, St. Leon-Rot, Germany) according to the manufacturer's instructions. To prepare substrates for the IFA, HEK293 cells were grown on sterile cover glasses, transfected, and allowed to express the recombinant protein for 48 hours. Cover glasses were washed with phosphate-buffered saline (PBS), fixed with either acetone or $1 \%(\mathrm{w} / \mathrm{v})$ formalin for 10 minutes at room temperature, air dried, cut into millimetersized fragments (biochips), and used as substrates in IFA (see below). For selected experiments, cells were transfected in standard T-flasks and the cell culture medium was harvested after 5 days. The medium was centrifuged at $20,000 \mathrm{~g}$ at $4^{\circ} \mathrm{C}$ 
for 20 minutes, and the resulting supernatant was stored in aliquots at $-80^{\circ} \mathrm{C}$ until further use.

Detection of anti-DNER antibodies by indirect immunofluorescence. IFA was conducted using slides with a mosaic of 9 biochip substrates: HEK293-DNER, HEK293CDR2/Yo, HEK293-CDR2L, and mock-transfected HEK293, each acetone- and formalin-fixed, as well as $4 \mu \mathrm{m}$ unfixed cryosections of monkey cerebellum (figure 1A). Each biochip mosaic was incubated with $70 \mu \mathrm{L}$ of PBS-diluted sample at room temperature for 30 minutes, washed with PBS-Tween, and immersed in PBS-Tween for 5 minutes. In the second step, fluorescein isothiocyanate-labeled goat anti-human $\mathrm{IgG}$ (Euroimmun, Lübeck, Germany) was applied and incubated at room temperature for 30 minutes. Slides were washed again with a flush of PBS-Tween and then immersed in PBS-Tween for 5 minutes. Slides were embedded in PBS-buffered DABCO containing glycerol (approximately $20 \mu \mathrm{L}$ per field) and examined by fluorescence microscopy with 460-490 nm LED excitation (EUROStar, Euroimmun). Results were evaluated by 2 independent observers with more than 10 years of professional experience. Positive and negative controls were included during each run. Samples were classified according to the fluorescence intensity of the transfected cells in direct comparison with CDR2/Yo, CRD2L-, and mock-transfected cells and control samples. A specific fluorescence of the transfected cells at a dilution of 1:10 or higher was considered positive. A staining of monkey cerebellum was scored as having an anti-Tr pattern when a distinct punctate immunoreactivity was detected in Purkinje cell dendritic tree and soma, as previously described. ${ }^{7,8}$ In addition, immunoreactivity against Purkinje cell cytoplasm was scored. Endpoint titers refer to the last dilution showing visible fluorescence. In competitive inhibition experiments, recombinant antigens were mixed with diluted serum sample 30 minutes prior to the IFA, as described in Stöcker et al. ${ }^{13}$

Purification of recombinant human DNER(ec) from HEK293 cells. The extracellular domain of DNER was expressed in HEK293 cells essentially as described for the fulllength protein. The cell culture supernatant was harvested after expression for 5 days. The recombinant protein was purified by immobilized metal affinity chromatography, as described for the extracellular domains of desmoglein 1 and $3 .{ }^{14}$ All steps were carried out at $4^{\circ} \mathrm{C}$. The fractionation of DNER(ec) was monitored by Western blot using a monoclonal antibody against hexahistidine and alkaline phosphatase anti-mouse IgG (Jackson ImmunoResearch Laboratories, West Grove, PA), as in reference 14 . The purified antigen was characterized by SDS-PAGE using the NuPAGE system (Invitrogen, Darmstadt, Germany) according to the manufacturer's instructions, Western blot, and MALDI-ToF fingerprinting, and MALDI-ToF tandem mass spectrometry after SDS-PAGE and tryptic cleavage. ${ }^{15}$
A
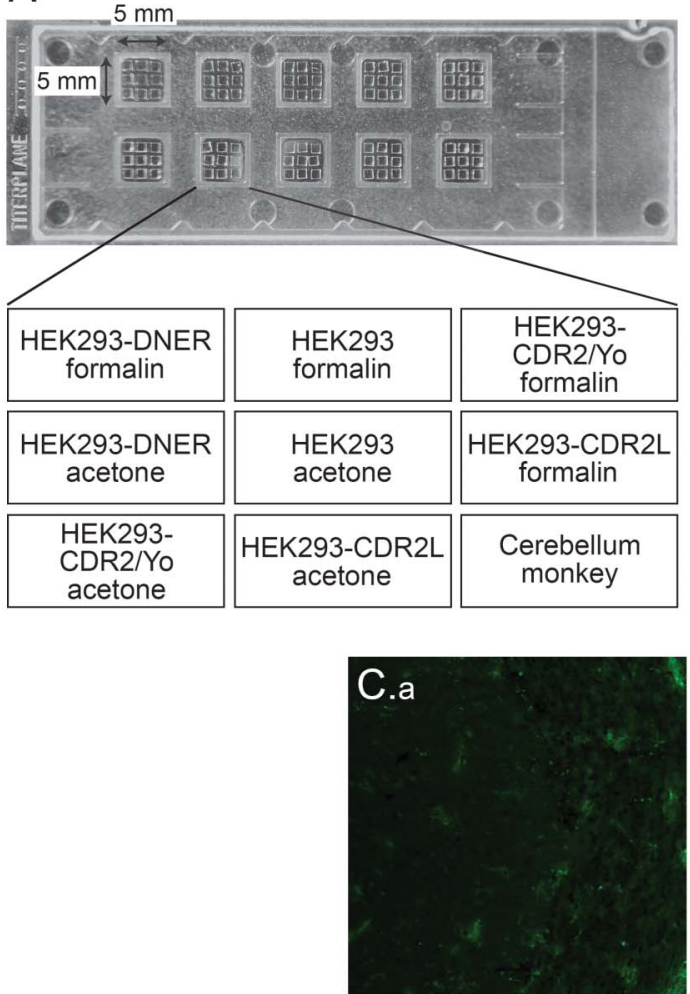
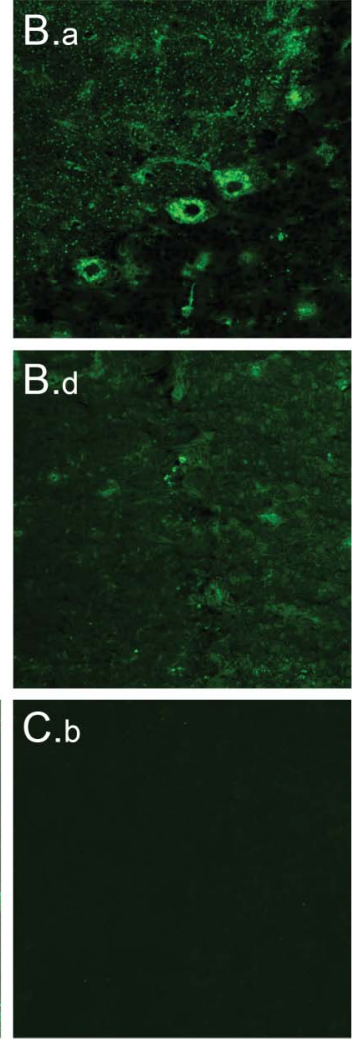
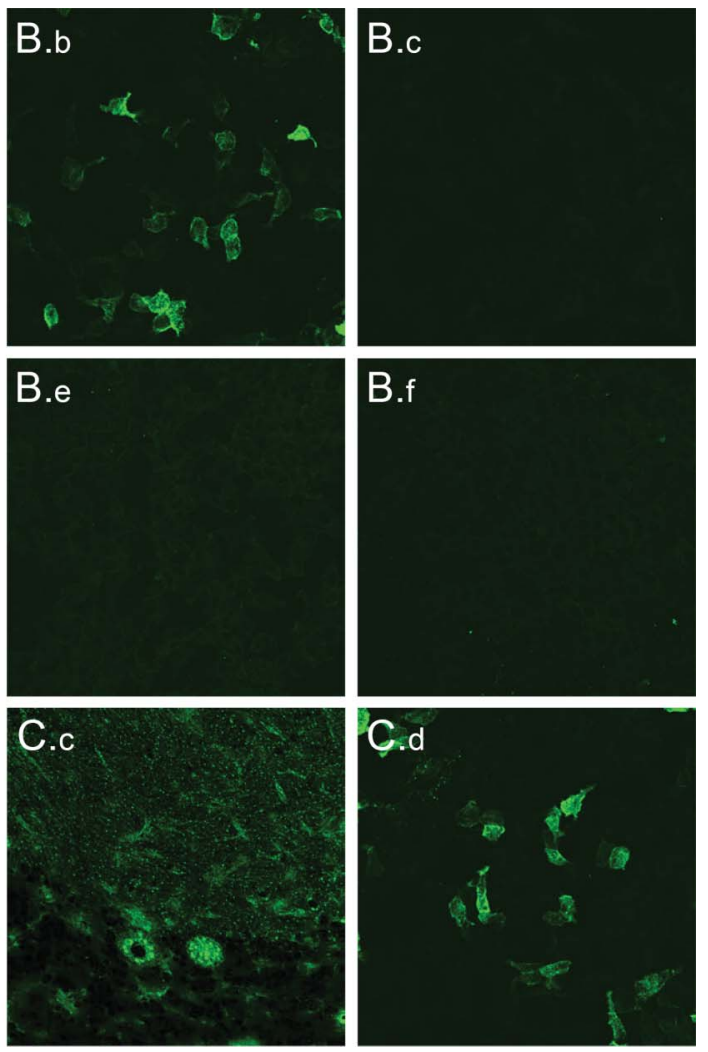

(A) Slide with 10 reaction fields as used for the study. Each reaction field contained 9 biochips with HEK293 cells expressing Delta/Notch-like epidermal growth factor-related receptor (DNER), CDR2/Yo, or CDR2L, and mock-transfected control cells fixed with either acetone or formalin as well as cryosections of monkey cerebellum. (B) Binding of serum IgG of a patient with paraneoplastic cerebellar degeneration and Hodgkin lymphoma (a-c) to Purkinje cell somata and dendritic trees (anti-Tr) pattern on monkey cerebellum ( $a, d)$ and to DNER-expressing cells $(b, e)$ but not control cells used as internal control $(c, f)$. None of these reactivities were seen with serum from controls (d-f). (C) Preincubation with a lysate of HEK293 expressing DNER (a, b) completely abolished the antiTr/DNER fluorescence ( $a$, c: monkey cerebellum; b, d: DNER-expressing cells), but it was not abolished following incubation with a similar lysate from wildtype HEK293 (c, d). 
Miscellaneous. All reagents were obtained from Merck or Sigma-Aldrich, Heidelberg, Germany, unless otherwise specified. Protein concentrations were determined by bicinchoninic acid assay (Sigma-Aldrich). All statistical analyses were performed using MedCalc V9.6.2.0 and SigmaPlot V10.0. A $p$ value of 0.05 was considered statistically significant.

RESULTS Determination of anti-DNER by indirect immunofluorescence. Prior to the testing of all sera, fixation experiments were conducted with representative, decoded, anti-Tr-positive control sera from Erasmus MC previously shown to bind to DNER. ${ }^{10}$ These sera reacted with both acetone- and formalin-fixed DNERtransfected HEK293 cells. However, formalin-fixed cells showed lower background staining, which allowed for more reliable evaluation of low-titer sera. Accordingly, only data obtained with the formalin-fixed DNER substrate were included in the study. In contrast to DNER, the control substrates CDR2/Yo and CDR2L were expressed intracellularly and, as expected, were only detected by anti-Yopositive control sera after acetone fixation but not after treatment with nonpermeabilizing formalin. Accordingly, acetone-fixed CDR2/Yo and CDR2L cells were used for the study. Storing experiments revealed that dust-free storing of desiccated slides containing the DNER, CDR2/Yo, and CDR2L substrates and mock-transfected control cells at $-20^{\circ}$ C for up to 12 months did not affect the outcome of individual tests.

All 38 sera with anti-Tr antibodies (as previously identified by the senders according to conventional or immunofluorescence-based immunohistochemistry) were positive for anti-DNER in the DNER RC-IFA but did not react with the control substrates (figure 1B). Moreover, all 6 anti-Yo-positive samples reacted with CDR2/Yo- and CDR2L-expressing cells but not with those expressing DNER or with the mock-transfected HEK293 cells. Of the other 201 control sera, none reacted with the recombinant cells or cerebellum. This corresponds to a sensitivity of $100 \% \quad(95 \%$ confidence interval [CI] $92.8 \%-100 \%)$ and a specificity of $100 \%(95 \%$ CI

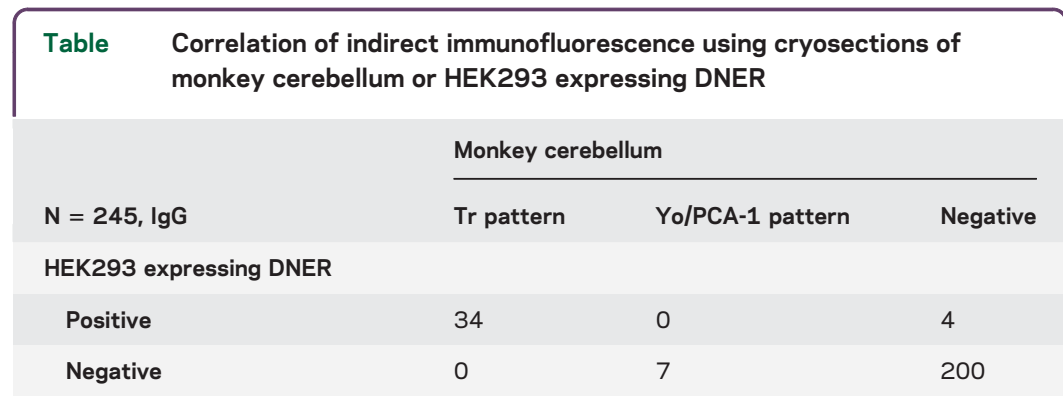

Abbreviations: DNER = Delta/Notch-like epidermal growth factor-related receptor; PCA = Purkinje cell cytoplasm antibody.

Fisher exact test showed highly significant correlations of anti-Tr pattern and anti-DNER positivity $(p<0.001)$.
$98.7 \%-100 \%)$ of the recombinant cell-based assay for anti-DNER.

When testing the same sera using the commercial non-recombinant IFA using monkey cerebellar tissue sections, only 34 of the 38 sera produced the typical anti-Tr pattern on tissue (table), corresponding to a sensitivity of $89.5 \%$ (95\% CI 80.6\%-89.5\%). The 4 discrepant sera were derived from patients with PCD and HL. All control sera were also negative for anti- $\mathrm{Tr}$ in the monkey tissue-based IFA (specificity 100\%, 95\% CI 98.7\%-100\%). One control serum showed a weak cytoplasmic Purkinje cell staining pattern but no anti-Tr-specific fluorescence at a 1:10 dilution.

Endpoint titers were determined in all 38 antiDNER-positive sera on the recombinant cells and monkey cerebellum. All but 3 sera showed higher titers when the recombinant cells were used in comparison to monkey tissue $(p<0.001$, Fisher exact test) (figure 2), which yielded low-titer or negative results in 20 of 38 cases. Full reproducibility was demonstrated with representative samples on the basis of 3 subsequent slide lots, and all criteria for the CE-labeling of in vitro diagnostics in norm ISO 13485 were fulfilled.

In neutralization experiments, lysates from HEK293-DNER and purified DNER(ec) abolished anti-DNER reactivities of human sera with recombinant cells and the corresponding anti-Tr reactivity on monkey cerebellum in a dose-dependent manner (figure 1C). High-titer sera required larger amounts of antigen than low-titer sera. In contrast, similar fractions of HEK293 cells expressing CDR2/Yo, mocktransfected HEK293, and the purified extracellular domain of desmoglein $3^{14}$ did not affect antiDNER or the anti- $\operatorname{Tr}$ reactivities.

DISCUSSION We report on the first well-standardized RC-IFA, which was developed to determine autoantibodies against Tr/DNER and then evaluated using samples collected in several European centers. In a blinded study of 245 sera, including a large panel of 38 sera with anti-Tr autoantibodies, the new assay yielded $100 \%$ sensitivity and specificity with respect to the serologic precharacterization that was performed at the contributing centers. In comparison to the reference procedure, which had to use the elaborate epitope blocking step as a confirmatory measure in many cases, RC-IFA proved to be easier to perform and interpret. Our results are in agreement with the initial report on the identification of DNER as the target antigen of anti-Tr antibodies ${ }^{10}$ and a subsequent independent confirmation study ${ }^{11}$ that used in-house RC-IFAs and significantly smaller sample cohorts.

RCA-IFA has already been shown to be a suitable method to sensitively and specifically detect other 
Figure 2 Comparative analysis of anti-Tr and anti-DNER titers as detected using mouse cerebellum and HEK293 cells transfected with human full-length DNER

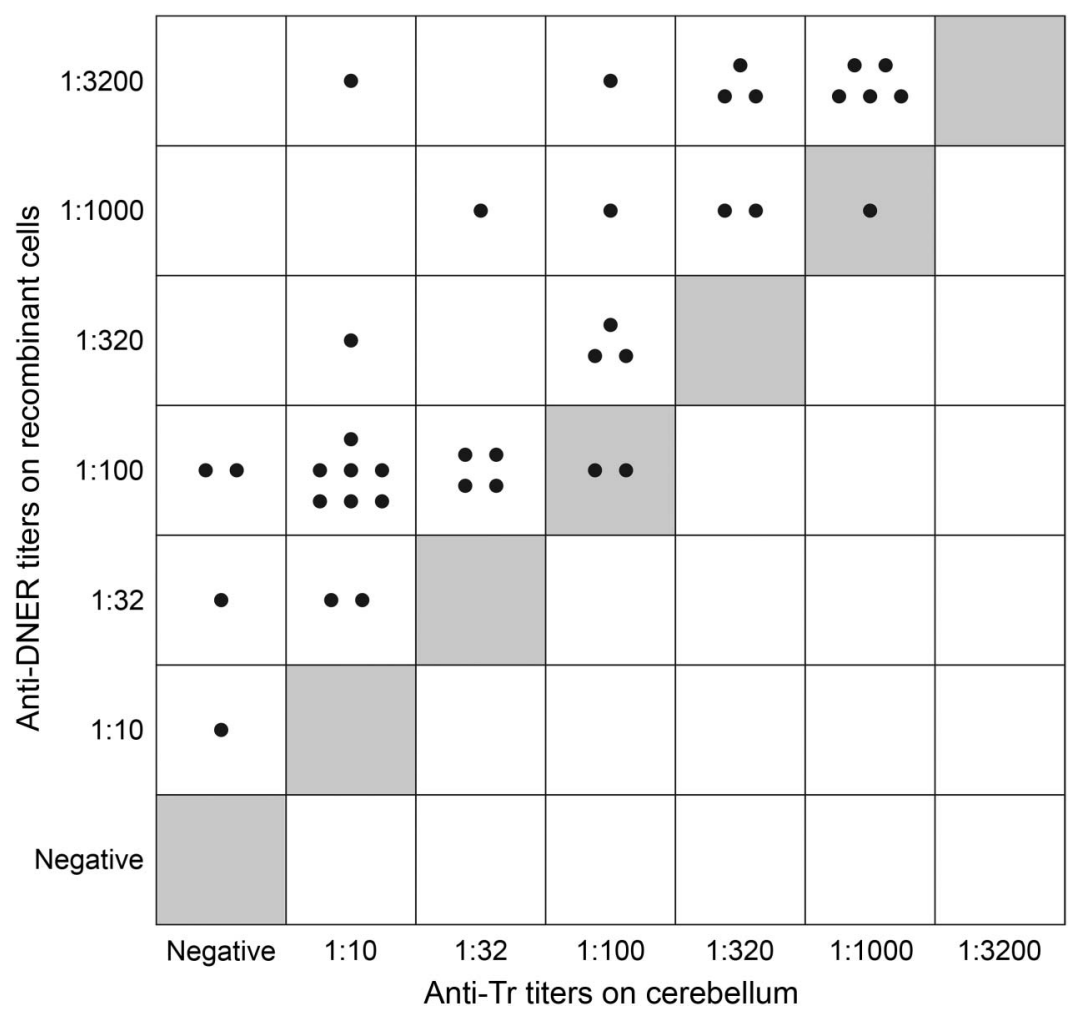

Each dot represents the endpoint titer of a single serum $(\mathrm{N}=38)$. All dots in individual squares represent identical results. Gray fields: line of equal endpoint titer between tissue and recombinant cells. DNER = Delta/Notch-like epidermal growth factor-related receptor.

anti-neural surface autoantibodies such as antiNMDA receptor ${ }^{16}$ or anti-aquaporin-4. ${ }^{17,18}$ Likewise, although intracellularly expressed, HEK293 cells expressing CDR2/Yo or CDR2L are apparently competent substrates for detecting autoantibodies against CDR2/Yo. All in all, recombinant cell substrates complement or even improve indirect immunofluorescence for the detection of paraneoplastic antineural autoantibodies for which cryosections of mammalian cerebellum are classically used.

By specific neutralization of the autoantibody reactions with recombinant full-length DNER expressed in HEK293, on the one hand, and the antiTr pattern on cerebellum using DNER(ec), we confirmed the earlier report on the exclusive presence of relevant epitopes in the extracellular domain of DNER..$^{10}$ We also demonstrated that the recombinant DNER(ec) construct is a fully competent antigen that may help in the development of a microplate ELISA or dot/lineblot for integration with other paraneoplastic neurologic syndrome markers such as $\mathrm{Hu}$, Yo, Ri, and CV2. ${ }^{19-21}$

As a rule, adult patients with subacute-onset cerebellar ataxia should be tested for anti-DNER and the other well-characterized onconeural antibodies. Two strategies can be used to detect anti-Tr/DNER antibodies. $^{22}$ First, an immunohistochemical screening can be performed using cryosections of cerebellum and then be confirmed in anti-DNER RC-IFA when the anti-Tr staining pattern is observed or suspected. Alternatively, direct screening can be performed using the anti-DNER RC-IFA; if the results are equivocal or the clinical data are highly suggestive, an additional immunohistochemistry could be performed as well. ${ }^{22}$ It is most preferable, however, to determine the autoantibodies by using a multiparametric approach using mosaics of tissue and recombinant cells, similar to the approach used in this study. Symptomatology-driven sets of test substrates can be assembled, and a broad spectrum of anti-neural autoantibodies can be tested for simultaneously. This allows for a faster final diagnosis of the patient.

\section{AUTHOR CONTRIBUTIONS}

C.P., L.K., and I.M.B. performed molecular biology work and were involved in antibody testing and microscopy. E.d.G., M.v.C.-H., V.R., J.H., L.S., F.C., S.J., R.V., B.W., D.F., and P.A.E.S.S. were involved in the clinical definition of the patients. C.P., L.K., W. Schlumberger, W. Stöcker, and P.A.E.S.S. were involved in the conception and organization of the research project and in the writing of the manuscript.

\section{ACKNOWLEDGMENT}

The authors thank Beatrice Schneider, Sabrina Voigt, Beatrice Witt, and Esther Hulsenboom for their excellent technical assistance. In France, samples were collected and stored with the help of Neurobiotec Bank and the Hospices Civils de Lyon. S.J. and B.W. are grateful to Mrs. Anna Eschlbeck and to the Nikon Imaging Center at the University of Heidelberg for excellent technical assistance.

\section{STUDY FUNDING}

No targeted funding reported.

\section{DISCLOSURE}

C. Probst is employee of and holds stock in Euroimmun. L. Komorowski is an employee of Euroimmun. E. de Graaf holds a patent for the detection of anti-DNER antibodies. M. van Coevorden-Hameete, V. Rogemond, J. Honnorat, and L. Sabater report no disclosure. F. Graus is on the editorial board for Lancet Neurology and has received research support from Fondo Investigaciones Santitarias. S. Jarius and R. Voltz report no disclosures. B. Wildemann has received travel funding and speaker honoraria from Bayer Healthcare, Biogen Idec, Merck Serono, Teva, and Sanofi-Aventis/Genzyme and has received research support from Biogen Idec, Merck Serono, Teva, Novartis, Biotest, DietmarHopp-Foundation, and German Ministry for Education and Research. D. Franciotta and I.M. Blöcker report no disclosures. W. Schlumberger is an Executive Board Member of Euroimmun AG. W. Stöcker holds patents for alibrationsstreifen für einen Immunoblot, Vorrichtung und Verfahren zur automatischen Fokussierung für die Mikroskopie schwach leuchtender Substrate, Verfahren zum spezifischen und quantitativen Nachweis von Antikörpern in einer Probe, zum Nachweis von AntiNMDA-Rezeptor-Autoantikörpern zum Einsatz in Diagnoseverfahren, Verfahren und Vorrichtung zur Bearbeitung von Proben biologischen Materials, Diagnosekit sowie Verfahren zur Untersuchung einer menschlichen Patientenprobe auf das Vorhandensein Neuromyelitis-opticaspezifischen Antikörpern, Testkit für die Labordiagnostik, Vorrichtung zur Steuerung einer Pipettiervorrichtung, Verfahren und Analysevorrichtung zur mikroskopischen Untersuchung eines Gewebeschnittes oder eines Zellausstriches, and Verfahren sowie Vorrichtung zur Inkubation von Patentientenproben; is the Head of the Board for Euroimmun Medizinische Labordiagnostika AG; is employed by Klinisch-immunologisches; and holds 
stock in Euroimmun Medizinische Labordiagnostika AG. P.A.E. Sillevis Smitt holds a patent on the detection of anti-DNER. Go to Neurology. org/nn for full disclosures.

Received September 12, 2014. Accepted in final form January 5, 2015.

\section{REFERENCES}

1. Darnell RB, Posner JB. Paraneoplastic Syndromes. New York: Oxford University Press, Inc.; 2011.

2. Graus F, Delattre JY, Antoine JC, et al. Recommended diagnostic criteria for paraneoplastic neurological syndromes. J Neurol Neurosurg Psychiatry 2004;75:1135-1140.

3. de Beukelaar JW, Sillevis Smitt PA. Managing paraneoplastic neurological disorders. Oncologist 2006;11:292-305.

4. Shams'ili S, Grefkens J, de LB, et al. Paraneoplastic cerebellar degeneration associated with antineuronal antibodies: analysis of 50 patients. Brain 2003;126:1409-1418.

5. Horwich L, Buxton PH, Ryan GM. Cerebellar degeneration with Hodgkin's disease. J Neurol Neurosurg Psychiatry 1966;29:45-51.

6. Trotter JL, Hendin BA, Osterland CK. Cerebellar degeneration with Hodgkin disease. An immunological study. Arch Neurol 1976;33:660-661.

7. Graus F, Dalmau J, Valldeoriola F, et al. Immunological characterization of a neuronal antibody (anti-Tr) associated with paraneoplastic cerebellar degeneration and Hodgkin's disease. J Neuroimmunol 1997;74:55-61.

8. Graus F, Gultekin SH, Ferrer I, Reiriz J, Alberch J, Dalmau J. Localization of the neuronal antigen recognized by anti- $\operatorname{Tr}$ antibodies from patients with paraneoplastic cerebellar degeneration and Hodgkin's disease in the rat nervous system. Acta Neuropathol 1998;96:1-7.

9. Bernal F, Shams'ili S, Rojas I, et al. Anti-Tr antibodies as markers of paraneoplastic cerebellar degeneration and Hodgkin's disease. Neurology 2003;60:230-234.

10. de Graaff E, Maat P, Hulsenboom E, et al. Identification of delta/notch-like epidermal growth factor-related receptor as the $\mathrm{Tr}$ antigen in paraneoplastic cerebellar degeneration. Ann Neurol 2012;71:815-824.

11. Greene M, Lai Y, Baella N, Dalmau J, Lancaster E. Antibodies to Delta/notch-like epidermal growth factor-related receptor in patients with anti-Tr, paraneoplastic cerebellar degeneration, and Hodgkin lymphoma. JAMA Neurol 2014;71:1003-8.

12. Bernal F, Graus F, Pifarre A, Saiz A, Benyahia B, Ribalta T. Immunohistochemical analysis of anti-Hu-associated paraneoplastic encephalomyelitis. Acta Neuropathol 2002;103:509-515.

13. Stöcker W, Otte M, Ulrich S, et al. Autoimmunity to pancreatic juice in Crohn's disease. Results of an autoantibody screening in patients with chronic inflammatory bowel disease. Scand J Gastroenterol Suppl 1987;139: $41-52$.

14. Schmidt E, Dähnrich C, Rosemann A, et al. Novel ELISA systems for antibodies to desmoglein 1 and 3: correlation of disease activity with serum autoantibody levels in individual pemphigus patients. Exp Dermatol 2010;19: 458-463.

15. Koy C, Mikkat S, Raptakis E, et al. Matrix-assisted laser desorption/ionization- quadrupole ion trap-time of flight mass spectrometry sequencing resolves structures of unidentified peptides obtained by in-gel tryptic digestion of haptoglobin derivatives from human plasma proteomes. Proteomics 2003;3:851-858.

16. Pruss H, Dalmau J, Harms L, et al. Retrospective analysis of NMDA receptor antibodies in encephalitis of unknown origin. Neurology 2010;75:1735-1739.

17. Jarius S, Probst C, Borowski K, et al. Standardized method for the detection of antibodies to aquaporin- 4 based on a highly sensitive immunofluorescence assay employing recombinant target antigen. J Neurol Sci 2010;291:52-56.

18. Jarius S, Wildemann B. Aquaporin-4 antibodies (NMO$\mathrm{IgG})$ as a serological marker of neuromyelitis optica: a critical review of the literature. Brain Pathol 2013;23: 661-683.

19. Jaeckle KA, Graus F, Houghton A, Cardon-Cardo C, Nielsen SL, Posner JB. Autoimmune response of patients with paraneoplastic cerebellar degeneration to a Purkinje cell cytoplasmic protein antigen. Ann Neurol 1985;18: 592-600.

20. Graus F, Cordon-Cardo C, Posner JB. Neuronal antinuclear antibody in sensory neuronopathy from lung cancer. Neurology 1985;35:538-543.

21. Honnorat J, Antoine JC, Derrington E, Aguera M, Belin MF. Antibodies to a subpopulation of glial cells and a $66 \mathrm{kDa}$ developmental protein in patients with paraneoplastic neurological syndromes. J Neurol Neurosurg Psychiatry 1996;61:270-278.

22. Hoftberger R, Dalmau J, Graus F. Clinical neuropathology practice guide 5-2012: updated guideline for the diagnosis of antineuronal antibodies. Clin Neuropathol 2012; 31:337-341. 


\title{
Neurology \\ Neuroimmunology \& Neuroinflammation
}

\author{
Standardized test for anti-Tr/DNER in patients with paraneoplastic cerebellar \\ degeneration \\ Christian Probst, Lars Komorowski, Esther de Graaff, et al. \\ Neurol Neuroimmunol Neuroinflamm 2015;2; \\ DOI 10.1212/NXI.0000000000000068
}

This information is current as of February 26, 2015

Updated Information \&

Services

References

Subspecialty Collections

Permissions \& Licensing

Reprints including high resolution figures, can be found at:

http://nn.neurology.org/content/2/2/e68.full.html

This article cites 21 articles, 4 of which you can access for free at: http://nn.neurology.org/content/2/2/e68.full.html\#\#ref-list-1

This article, along with others on similar topics, appears in the following collection(s):

All Movement Disorders

http://nn.neurology.org//cgi/collection/all_movement_disorders

Gait disorders/ataxia

http://nn.neurology.org//cgi/collection/gait_disorders_ataxia

Paraneoplastic syndrome

http://nn.neurology.org//cgi/collection/paraneoplastic_syndrome

Information about reproducing this article in parts (figures,tables) or in its entirety can be found online at:

http://nn.neurology.org/misc/about.xhtml\#permissions

Information about ordering reprints can be found online: http://nn.neurology.org/misc/addir.xhtml\#reprintsus

Neurol Neuroimmunol Neuroinflamm is an official journal of the American Academy of Neurology.

Published since April 2014, it is an open-access, online-only, continuous publication journal. Copyright $(\subseteq$ 2015 American Academy of Neurology. All rights reserved. Online ISSN: 2332-7812.

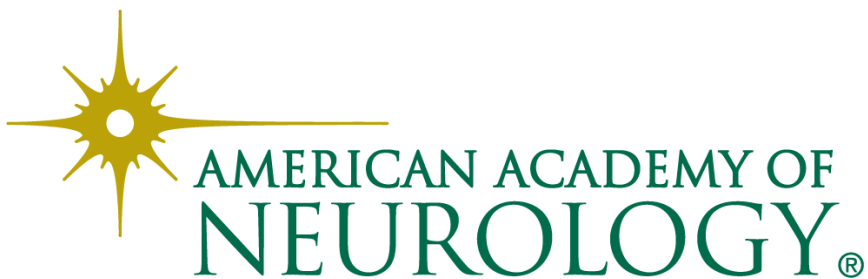

